\title{
Influence of Air Temperature on School Teachers' Mood and the Perception of Students' Behavior
}

\author{
Salvador Boix-Vilella ${ }^{1} \mathbb{C}$, Elena Saiz-Clar ${ }^{2}$, Eva León-Zarceño ${ }^{3} \mathbb{C}$ and Miguel Angel Serrano ${ }^{4, *}$ (I) \\ 1 Facultad de Humanidades y Ciencias Sociales, Universidad Isabel I, 09003 Burgos, Spain; \\ salvador.boix@ui1.es \\ 2 Department of Methodology in the Behavioural Sciences and Health, UNED, 28040 Madrid, Spain; \\ esaiz@bec.uned.es \\ 3 Departamento de Ciencias del Comportamiento y Salud, Universidad Miguel Hernández de Elche, \\ 03202 Elche, Spain; eleon@umh.es \\ 4 Department of Psychobiology, University of Valencia, 46010 Valencia, Spain \\ * Correspondence: m.angel.serrano@uv.es
}

check for updates

Citation: Boix-Vilella, S.; Saiz-Clar, E.; León-Zarceño, E.; Serrano, M.A. Influence of Air Temperature on School Teachers' Mood and the Perception of Students' Behavior. Sustainability 2021, 13, 9707. https:// doi.org/10.3390/su13179707

Academic Editor: Naomi T. Krogman

Received: 2 July 2021

Accepted: 22 August 2021

Published: 30 August 2021

Publisher's Note: MDPI stays neutral with regard to jurisdictional claims in published maps and institutional affiliations.

Copyright: (c) 2021 by the authors. Licensee MDPI, Basel, Switzerland. This article is an open access article distributed under the terms and conditions of the Creative Commons Attribution (CC BY) license (https:// creativecommons.org/licenses/by/ $4.0 /)$.

\begin{abstract}
This study investigates how temperature, inside and outside the classroom, influence teachers' mood and mental fatigue as well as the perceived students' behavior. Two daily random measurements of the temperature inside various classrooms were taken for 7 months. Mood, mental fatigue, and perception of students' behavior were evaluated for the teachers. Daily external temperature data were obtained from the State Agency of Meteorology. Results showed that indoor temperature, indoor humidity, and the difference between outdoor/indoor temperature significantly explain a worse perception of mood of the teachers and a worse perception of students' behavior that influences perception of students' behavior.
\end{abstract}

Keywords: school building; air temperature; teaching quality; teachers' mood; students' behavior

\section{Introduction}

Currently, the Intergovernmental Panel on Climate Change (IPCC) points out that global warming has led to a rise in temperatures around the world [1] and is generating changes in climate patterns that have major public health implications [2]. A recent study focusing on mood and seasons confirms that spring followed by winter and summer are the most representative time of the year to go to the health services with problems related to mood disorders [3]. In the specific case of the countries that make up the Iberian Peninsula, Portugal and Spain, experts have noted that there is an annual increase in the number of days of extreme heat [4].

Despite the fact that the study of temperature in the socio-labor context and general increase in temperatures have traditionally been ignored, it is increasingly common to find studies that are concerned with evaluating the thermal comfort of educational centers $[5,6]$ because it is certain that environmental conditions affect productivity, performance and well-being $[7,8]$. In this regard, most existing studies focus on assessing the indoor comfort of schools because students spend more time in school than in any other building, except the home [9]. Moreover, it is estimated that there will be a steady increase in a number of European citizens staying at risk of heat stress, which could reach $48.4 \%$ by 2050 , unless there are major policy changes towards sustainability [10]. Specifically, within the Mediterranean climate area, there are studies focusing on schools that reflect complaints about high temperatures in primary classrooms during the warmer seasons [11,12]. This particular interest in studying the thermal comfort levels of schools aims to improve the conditions of the indoor spaces in which both teachers and students reside for much of the day [13-15] as prolonged exposure to extreme conditions ends up affecting physical, cognitive and mood performance [16,17]. Currently, the scientific evidence shows that 
there are associations between student academic performance and type of ventilation system, ventilation rates, fine particle counts, and ozone $\left(\mathrm{O}_{3}\right)$ and carbon dioxide $\left(\mathrm{CO}_{2}\right)$ concentrations [18]. The thermal and air quality conditions can reduce the performance by $5-10 \%$ for adults and by $15-30 \%$ for children [19]. Among strategies to improve the thermal comfort is to upgrade air ventilation systems of the classroom especially for the urban school type [20]. In addition, it also seeks to reduce energy consumption because school buildings represent a significant part of the building stock, according to the Federation of European Heating, Ventilation and Air Conditioning Associations (REHVA; [21]).

The Australian society has already spoken of neglect in many of the policies for school building design, classroom design, class sizes and school landscaping just over two decades ago [16]. Another more recent study pointed out the need to create more favorable environments for learning; for example, the views from the classroom to green landscapes have positive impacts on recovery from mental fatigue and stress [22]. Another problematic issue is the fact that the orientation of most classrooms, primarily aimed to gain natural light through large windows, additionally increase temperature, discomfort and reduce student performance [9].

In relation to thermal comfort, there are two main models: rational (RTC; [23]) and adaptive (ATC; [24]). Although Fanger's RTC model was based on studies conducted with university students in climate-controlled environments, studies have argued that it could not accurately predict thermal comfort levels in real-world classroom conditions [25]. The second model, based on the assumption of indoor comfort, depends largely on the relationship between the indoor operating temperature and the outdoor temperature [26] The hypothesis on which this model is based is that people can modify their comfort expectations when they are aware of the weather outside and can make changes in their space such as opening a window to improve environmental conditions [27].

The International Organization for Standardization (ISO; [28]) 7730 and the American Society of Heating, Refrigeration and Air Conditioning Engineers (ASHRAE; [29].) agree on defining thermal comfort as a mental condition that expresses satisfaction with the environment, pointing out that the feeling of comfort is different for each person. The most widely used indicator of thermal comfort is air temperature; however, air temperature by itself is not a valid or accurate indicator of thermal comfort because it is influenced by other variables such as average radiant temperature, air speed, the pressure of water vapor in ambient air, the level of activity, and the person's clothing [30]. Other studies collect the importance of illumination, noise and air pollution in thermal comfort [31,32], so all these variables should be taken into account when analyzing mood, mental fatigue and the quality of teaching.

Despite having different thermal comfort standards such as ISO 7730, EN 15251 or the ASHRAE 55 standard, it has been shown that they are mostly inappropriate for evaluating the thermal environments of the classroom [9]. A recent study also argues that the adaptive model is an inappropriate metric to study thermal comfort in educational buildings in the local context [33].

Questionnaires are a widely used tool to evaluate the sensation of thermal comfort [20]. The answers of the participants are conditioned by physical parameters (e.g., mean radiant temperature, levels of $\mathrm{CO}_{2}$, etc.); physiological parameters (e.g., age, metabolism, etc.); psychological parameters (e.g., tiredness, enthusiasm, etc.) [34,35]. Moreover, the answers are conditioned by individual and subjective perception [34].

As for indoor temperatures, it is known that work performance is significantly affected by temperatures above $26^{\circ} \mathrm{C}$ and low relative humidity levels, specifically those below $40 \%$ [36]. Thus, experts agree that the increase in temperature has a negative impact on health, particularly on fatigue [37]. High levels of relative humidity in the air, combined with high temperatures, have been associated with greater fatigue of healthy people [38], with fatigue (subjective perceptions of weakness, lack of energy and tiredness) being an important bio-alarm for health that contributes to deterioration of teaching quality and generates absences from work among teachers [39]. 
Staying in the context of school atmosphere, teachers who are more enthusiastic during conduct of their classes allow students to observe this enjoyment, thus favoring learning [40]. Therefore, the quality of teaching would also be linked to the emotions present in the classroom and the implications of educational behavior between students and teachers [41]. The proposed model by Frenzel et al. [40] points out that teachers' emotions have a reciprocal influence on their instructional behavior (i.e., cognitive stimulation, motivation and social support), which in turn influences their students' results. In this line, Hartel and Page's [42] theory of the crossover states that emotions can be directly or indirectly caused by the emotions of others. Finally, the model of Klieme et al. [43] proposes specific interrelations theoretically derived between the dimensions of teaching quality (emotional support, classroom management and educational support for students) and the cognitive, affective and motivational characteristics of students. Mood generally refers to diffuse low-intensity states that can last from hours to months, yet in the normal course of classroom events, strong emotions (e.g., fear) may be less evident than mood [44].

Therefore, there is evidence to suggest that thermal conditions in the classroom can negatively affect teachers' mood and fatigue, which can influence the quality of their teaching and cause a negative perception of students' behavior, who end up losing their interest in the class, asking to go out to drink water or go to the playground before the period established for this purpose [45]. Based on the relationships between the variables presented here, the aim of this study was not to study how thermal comfort influences teachers' perceptions but determine the extent to which objective variables as temperature and humidity (indoor, outdoor and indoor-outdoor difference) influence teachers' mood, as well as other variables associated with teaching, such as perception of students' behavior, teaching quality and mental fatigue. For this purpose, the temperature (indoor and outdoor) and humidity of several classrooms were measured, and teachers were asked about their mood, mental fatigue, perceived quality of their class, as well as the teachers' perceived level of student behavior.

\section{Materials and Methods}

\subsection{Participants}

In the present study, 242 measurements of indoor temperature and humidity were taken in classrooms of a public Infant and Primary School in the province of Alicante (Spain). The school building has two classrooms on the ground floor, which correspond to the classrooms of Infant Education for 3-year-old children, a gymnasium and the school canteen. On the first floor of the school building, there are four infant education classes ( 4 and 5 years old), three primary education classrooms (two third and one fourth year), offices, an IT suite and a teachers' room. On the second floor are located five primary classes (one fourth, two fifth and two sixth), the library, the music class and a classroom for specialists. Finally, it should be noted that on each floor there are toilets in the different corridors.

The dimensions of the classrooms range from $35 \mathrm{~m}^{2}$ in primary classes to $38 \mathrm{~m}^{2}$ in the infant stage. The ceilings of the center have a minimum height of $3.1 \mathrm{~m}$. The school building analyzed is not air-conditioned and is ventilated by operable windows. In the colder months, the school has central heating, and it is on for the first two hours in the morning in all classes.

Talking about the number of students in class, this school has an average of $22.61 \mathrm{stu}-$ dents. Infant classes register an average of 21.67 students, while in primary education the average number of students is 23.08 .

Two random measurements were taken each day and the two teachers in those classrooms (those who were teaching) were responsible for answering a short questionnaire. A total of 27 teachers were working in the school and 25 of them ( 7 men and 18 women) participated in the study on a completely voluntary basis. By the educational stage, 7 infant school teachers $(28 \%)$ and 18 primary school teachers $(72 \%)$ participated. The average age of the participating teachers was 38.24 years, and they had an average teaching experience 
of 11.88 years. Of the 242 total measurements, 72 were carried out in nursery classes $(29.8 \%)$ and 170 in primary classes $(70.2 \%)$. Women participated in these measurements 153 times $(63.3 \%)$, and the remaining 89 times were men $(36.8 \%)$. Because the participation of the 25 teachers in the 242 participations was random, the resulting average age (39.8 years) and years of experience (12.05) vary slightly from the initial data.

\subsection{Instruments}

\subsubsection{Temperature and Humidity inside the Classes}

For the measurement of temperature and humidity, 2 identical ThermoPro brand temperature meters were used with an accuracy of $\pm 1{ }^{\circ} \mathrm{C}$. Both had a temperature range of $-50{ }^{\circ} \mathrm{C}$ to $70{ }^{\circ} \mathrm{C}$ and a relative humidity range of $10 \%$ to $99 \%$.

\subsubsection{Temperature and Humidity outside the School Building}

The daily external temperature data were obtained by the researchers of the present study from the State Agency of Meteorology (AEMET). These data are recorded daily in one of the meteorological stations in the city of Elche, specifically at latitude $38^{\circ} 17^{\prime} 15^{\prime \prime}$ North and longitude $0^{\circ} 40^{\prime} 50^{\prime \prime}$ West and at an altitude of $110 \mathrm{~m}$ above sea level. The AEMET meteorological station from which the data on temperature and external relative humidity have been obtained is located very close to the school. For this reason, it has not been considered necessary to take these daily measurements.

\subsubsection{Questionnaire for Teachers}

Based on a scale developed by us, we evaluated the perceived levels of mental fatigue, mood, teaching quality and students' behavior. To complete the scale, teachers were asked to mark with a cross a number (from 0 to 100) on each of the four scales evaluated, which independently measured the previous variables associated with teaching. In each scale, the value 0 corresponds to a greater or lesser incidence that is supported by an icon to clarify the meaning of the teacher's response. Thus, for example, a value of 0 implies the absence of mental fatigue, a low level of teaching quality, a worse mood and good students' behavior. See Figure 1.

\subsection{Procedure}

The procedure used in this study is based on the work of Biondi et al. [45] where the temperature and humidity inside the classroom and outside the building are collected daily. In addition, this study measured 3 climate variables (indoor and outdoor temperature and humidity) and surveyed different teachers about their mood, the perceived quality of their classes, as well as the behavior they perceive of their students, in order to test the influence of objective climate variables on the perception of basic aspects of teaching. In this sense, it is not a specific study on thermal comfort because they were not asked about temperature sensations, as this was not a variable that was the object of study, given its subjectivity.

In this study, measurements were taken in three seasons: autumn, winter and spring. The difference is that in the present work, 2 measurements were acquired daily at a specific time during 7 school months, and in the previous one, only 2 measurements were taken in each station but with a recording interval of $1 \mathrm{~min}$ between 10:00 am and 4:00 $\mathrm{pm}$. The school building analyzed were non-air-conditioned and ventilated by operable windows. 
We need to know your levels of mental fatigue, the quality level of your teaching, your mood and the students' behaviour. To do this, you have to mark on the 4 scales with a cross.

Scale 1

Could you indicate your mental fatigue level that you perceive at the moment? $(0=$ without fatigue $/ 100=$ high fatigue level).

(-)

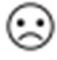

\begin{tabular}{|l|l|l|l|l|l|l|l|l|l|l|l|l|l|l|l|l|l|l|l|l|}
\hline 0 & 5 & 10 & 15 & 20 & 25 & 30 & 35 & 40 & 45 & 50 & 55 & 60 & 65 & 70 & 75 & 80 & 85 & 90 & 95 & 100 \\
\hline & & & & & & & & & & & & & & & & & & & & \\
\hline \multicolumn{10}{|c|}{ Scale 2} \\
\hline
\end{tabular}

Could you indicate the quality level of your teaching in the last session? $(0=$ bad session $/ 100$ = excellent session).

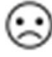

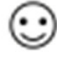

\begin{tabular}{|c|c|c|c|c|c|c|c|c|c|c|c|c|c|c|c|c|c|c|c|}
\hline $\begin{array}{ll}0 & 5 \\
\end{array}$ & 10 & 15 & 20 & 25 & 30 & 35 & 40 & 45 & 50 & 55 & 60 & 65 & 70 & 75 & 80 & 85 & 90 & 95 & 100 \\
\hline & & & & & & & & & & & & & & & & & & & \\
\hline
\end{tabular}

Could you indicate the mood that you are feeling at the moment? $(0=\mathrm{bad} \operatorname{mood} / 100=$ excellent mood).

$\because$

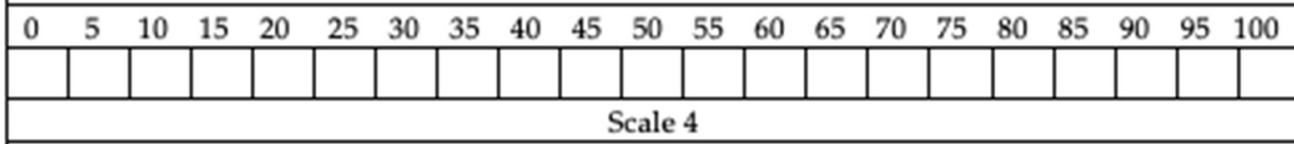

Could you indicate the students' behaviour in the last session? $(0=$ misbehaviour $/ 100=$ excellent behaviour).

$\circlearrowleft$

\begin{tabular}{|l|l|l|l|l|l|l|l|l|l|l|l|l|l|l|l|l|l|l|l|l|}
\hline 0 & 5 & 10 & 15 & 20 & 25 & 30 & 35 & 40 & 45 & 50 & 55 & 60 & 65 & 70 & 75 & 80 & 85 & 90 & 95 & 100 \\
\hline & & & & & & & & & & & & & & & & & & & & \\
\hline
\end{tabular}

Figure 1. Scales of mental fatigue, teaching quality, mood and students' behaviour used.

The collection of the meteorological data in the different classrooms was carried out at the end of the school period with students, specifically at $2 \mathrm{pm}$. At the same time, the teacher completed a short questionnaire with 4 subscales on their level of mental fatigue, mood, quality of teaching and students' behavior. The two thermometers used were randomly placed in two classrooms at $1 \mathrm{pm}$ and the temperature and relative humidity measurements were taken one hour later. The thermometers were placed inside the classroom, depending on the classroom - on top of a low cabinet or a shelf, at a height of $1.50 \mathrm{~m}$ and opposite the windows. The measurements began on 3 October 2017 and ended on 27 April 2018. During those 7 months, the seasons of autumn, winter and spring were covered.

With respect to ethical principles, this study complies with the principles of the latest reform of the Declaration of Helsinki of the World Medical Association [46]. Furthermore, the procedure of the work has been approved by the ethics committee of the University Miguel Hernández.

\subsection{Statistical Analysis}

A structural equation model (SEM) was used to respond to the objective. Specific steps are explained in the results section. The statistical analyses for the preparation of this work were carried out with SPSS Software version 19 and LISREL v.9.30. 


\section{Results}

\subsection{Analysis of the Conditions of Application of the Structural Equation Technique}

In order to determine whether the assumption of linearity between the variables was not affected by the presence of outliers or anomalies, the assumption of statistical normality on the previously typed variables was analyzed. It was verified that only humidity $(Z=1.285 ; p>0.050)$ and temperature $(Z=1.177 ; p>0.050)$ were distributed according to the normal distribution. Typified variables allowed us to verify the absence of outliers above the 2.5 standard deviations. The rest of variables presented asymmetric distributions towards the right (for example, teaching quality and mood), which implies a bias towards extremely positive valuations in both variables. The variables of mental fatigue and student behaviour were homogeneous throughout their distribution. Therefore, the non-normal variables were logarithmically transformed, but this transformation did not correct the lack of adjustment to the normal distribution. In view of the violation of this assumption, robust estimators were used through bootstrap sampling and the choice of nonparametric estimators.

Despite the fact that the lack of adjustment indicates that the considered variables present different distributions, the magnitude of the association between them was checked using the Spearman.-Brown test. See Table 1. This matrix showed the existence of nonzero and moderate-high magnitude correlations between different pairs of variables.

Table 1. Descriptive statistics and correlation matrix between variables.

\begin{tabular}{|c|c|c|c|c|c|c|c|c|c|}
\hline & Mean & SD & $\begin{array}{c}\text { Temperature } \\
\text { Indoor }\end{array}$ & $\underset{\text { Indoor }}{\text { Humidity }}$ & $\begin{array}{l}\text { Difference of } \\
\text { Temperature }\end{array}$ & Mood & $\begin{array}{l}\text { Students' } \\
\text { Behaviour }\end{array}$ & $\begin{array}{l}\text { Mental } \\
\text { Fatigue }\end{array}$ & $\begin{array}{l}\text { Quality } \\
\text { Level of } \\
\text { Teaching }\end{array}$ \\
\hline Temperature indoor & 21.5 & 2.6 & 1 & & & & & & \\
\hline Humidity indoor & 41.7 & 5.9 & $0.412^{* *}$ & 1 & & & & & \\
\hline $\begin{array}{l}\text { Difference } \\
\text { temperature }\end{array}$ & -1.9 & 3.0 & $0.235 * *$ & 0.066 & 1 & & & & \\
\hline Mood & 68.0 & 19.9 & -0.141 * & -0.105 & $0.200 * *$ & 1 & & & \\
\hline $\begin{array}{c}\text { Students' } \\
\text { behaviour }\end{array}$ & 57.4 & 24.1 & 0.110 & -0.039 & -0.047 & $-0.224^{* *}$ & 1 & & \\
\hline Mental fatigue & 55.4 & 24.9 & 0.114 & -0.049 & -0.002 & $-0.322 * *$ & $0.549^{* *}$ & 1 & \\
\hline $\begin{array}{l}\text { Quality level of } \\
\text { teaching }\end{array}$ & 67.0 & 19.2 & $-0.202 * *$ & -0.160 * & 0.074 & $0.650 * *$ & $-0.188^{* *}$ & $-0.180 * *$ & 1 \\
\hline
\end{tabular}

${ }^{*} p<0.050 ;{ }^{* *} p<0.010$.

\subsection{Path Analysis}

The next phase of the study was devoted to Path Analysis, which, based on the literature presented in the introduction, culminated in the proposal of a model that allowed us to understand the effect that environmental factors have on behavior. The specific objective of this model was to know and estimate the effect that certain environmental conditions have on the functioning of teachers and students in the school context. Therefore, it is important to emphasize that the objective of this model is not to reach the maximum of prediction (given that these environmental physical conditions are not unique determinants in behavior), but to clarify the model that allows us to better understand the effect of these environmental variables on behavior in the classroom dynamics.

After testing different structures, it has been found that the model shown in Figure 2 is the one that obtains the best adjustment rates. Three predictive variables are considered: the indoor temperature of the classroom, the indoor humidity, and the difference between the indoor and outdoor temperature in the classroom. The relationship between these three predictors were included within the model because this relationship exists between them for purely physical reasons. These predictors connect with two variables: the teacher's mood and the teacher's perception of the students' behavior in the classroom. (It is reasonable to think that if certain environmental characteristics that are shared by all the individuals living in that physical environment affect one component of the system (for example the teacher's mood), they will also affect the rest of the components of the system (for example the students' behavior). 


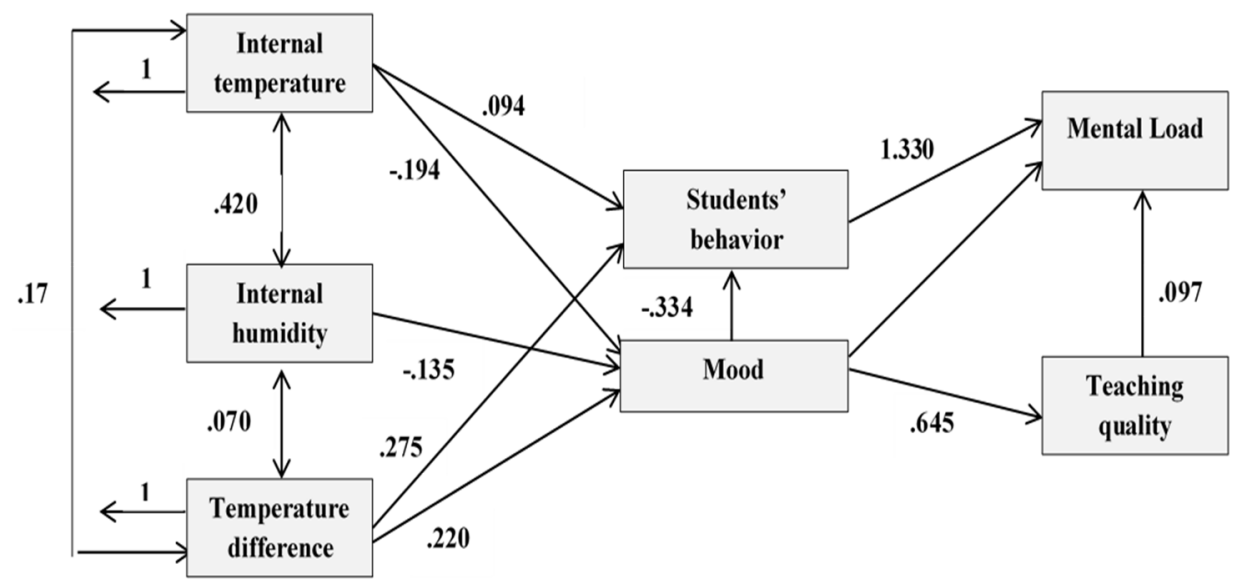

Figure 2. Model explaining environmental conditions in the operation of teachers and their students. The numerical value represented next to the box of an observed variable is the proportion of variance shared by the indicator and the latent variable (similar to communality) and not attributable to measurement error.

Specifically, it was found that both indoor temperature and the difference with respect to the outdoor temperature are negatively related to the teacher's mood (Figure 2). This relationship implies that the higher the indoor temperature, and the higher the outdoor temperature with respect to the indoor temperature the worse the mood of the teachers. Similarly, the higher the indoor temperature $\left(X \approx 22^{\circ} \mathrm{C}\right)$ and the greater the difference between outdoor and indoor temperatures, the worse the perception of students' behavior. Moreover, this is also significantly influenced in the present model by the teacher's mood, so the worse teacher's mood, the worse perception of students' behavior.

Finally, teachers' mood is significantly related to perceived teaching quality, so the worse the teachers' mood, the worse their perception of performance quality. Finally, the negative perception of students' behavior is directly related to greater mental fatigue in teachers.

\subsection{Adjustment Statistics (Validity of the Model)}

Once the model has been built, it is necessary to study the different adjustment indexes to check the validity of the model. For this purpose, in SEM the validation of the proposed model is done by minimizing the error or discrepancy between the empirical covariance matrix and the covariance matrix predicted by the SEM model. For this purpose, a set of indices is available that indicate the acceptable or not degree of discrepancy between both covariance matrices. The first of these is the absolute fit index $\chi^{2}$ that directly contrasts the null hypothesis that the error is null. In the present model, a value of $\chi^{2}=7.522$ has been obtained with a $p=0.377$ that would indicate that the present model is indeed capable of reproducing the empirical covariance matrix. Due to the sensitivity of this statistic to the sample size when committing a Type I error, it is common to combine it with other indices such as the family of relative fit indices that compare the fit of the proposed model with the fit of another with a worse fit or a null model that contains all the possible relationships. From the study of the family of relative fit indices (Table 2), indexes higher than 0.950 are obtained in all cases, which indicates that the present model is capable of accurately estimating the covariance matrix. 
Table 2. Model adjustment statistics.

\begin{tabular}{lcc}
\hline & $\begin{array}{c}\text { Criteria (Ruiz, Pardo, \& } \\
\text { San Martin, 2010) }\end{array}$ & Results \\
\hline Global adjustment & & $p=0.377$ \\
\hline Test $\chi^{2}$ & $>0.050$ & 1.074 \\
$\chi^{2} / f d$ & $<3$ & \\
\hline Relative Adjustment indexes & & 0.961 \\
\hline Normed Fit Index (NFI) & $>0.950$ & 0.991 \\
Non-Normed Fit Index (NNFI) & $>0.950$ & 0.997 \\
Comparative Fit Index (CFI) & $>0.950$ & 0.997 \\
Incremental Fit Index (IFI) & $>0.950$ & 0.320 \\
\hline Parsimonia index & & \\
\hline Parsimony Normed Fit Index (PNFI) & $\approx 1$ & 0.994 \\
\hline Other adjustment indexes & $>0.950$ & 0.976 \\
\hline Goodness of Fit Index (GFI) & $>0.950$ & 0.039 \\
$\quad$ Adjusted Goodness of Fit Index (AGFI) & $\approx 0$ & 0.018 \\
Standardized Root Mean Square & $<0.080$ & \\
Residual (SRMR) & & \\
Root Mean Square Error of & &
\end{tabular}

A third index is PNFI, which provides information about model fit in terms of the number of parameters used in the model in relation to the problem of model over-fit. Because the PNFI must tend towards unity, the value obtained in our work (Table 2) prevents us from considering it appropriate. However, this interpretation is contradicted by the result of the relative index of adjustment NFI, which is also considered as an index of parsimony. In this case, for NFI (Table 2) we have obtained a result that exceeds the cut-off value proposed in Ruiz et al. [47]. Thus, authors such as Hooper et al. [48] point out that PNFI may underestimate model fit when dealing with complex models that require a high number of interactions and parameters, recommending their interpretation along with the rest of the fit indices. RMSEA can also be considered as an index of model parsimony because it penalizes models with an inadequate number of parameters [48]. The most restrictive criteria for RMSEA place the cut-off point at values below 0.080 [47] to consider the model fit. In the present case, this value is considerably lower than the proposed cut-off point. Therefore, despite the fact that PNFI would indicate a problem of redundancy, the values obtained in NFI and RMSEA encourage us to consider that the present model is adjusted in terms of parsimony considering the number of parameters introduced in it adequately. Finally, the remaining parameters considered (GFI and AGFI) that evaluate other dimensions of model fit also exceed the cut-off points traditionally considered. Therefore, at a global level, considering the 11 indices used to evaluate the model's fit, it can be concluded that the model presents evident fit criteria in terms of parameter and relationship parsimony, as well as in terms of the absence of discrepancy between the empirical and estimated variance-covariance matrices.

\section{Discussion}

Before discussing results, it is important to consider that the present study has not measured the values of the operating temperature or the effects of illumination, acoustic and indoor air quality that are considered important to have a complete evaluation of thermal comfort. In fact, it is not a study on thermal comfort, but aims to study how objective climate variables indirectly influence teachers' perceptual variables. If the present study had included other physical, physiological or psychological variables in the analysis, the results obtained could be different. Moreover, the scientific literature shows the difficulty that exists in this type of study because the physical and physiological parameters of thermal 
comfort analyzed have not coincided with the exchange of energy body environment because the responses are conditioned by a subjective perception [34]. Therefore, the results should be interpreted cautiously because only indoor and outdoor temperature and humidity has been measured.

Having made that clear, the results show the influence of air temperature on the work of teachers. In addition, they are consistent with those obtained in previous studies in other sectors (in which Heating, Ventilating and Air Conditioning (HVAC) systems were not evaluated either) which shows how exposure to high temperatures negatively affects the optimal development of work functions [17]. Specifically, it is observed that indoor temperature and the difference between this and the outdoor temperature has a negative influence on the teachers' mood, which, in turn, negatively influence on perception of a students' behavior. This result is important from the point of view that not only does the indoor temperature of the classroom have a negative influence on the teachers' mood, but also the difference between the outdoor and indoor temperature is an important factor that influences mood and the perception of student behavior. In this sense, it is considered that not only the control of the classroom temperature should be taken into account, but also that it should be regulated according to the outside temperature because this difference in temperature could be relevant to the influence of the inside temperature. To our knowledge, there are no studies that reveal this influence on mood, although it has been described that, in the case of professional drivers, high outside temperatures can cause adverse moods, a greater number of errors, and can even trigger road accidents [17].

On the other hand, it is also highlighted as an interesting result of this study that mood influences the perception of teaching quality. Moreover, the more negative the perception of students' behavior, the more the teacher increases their perception of fatigue. In this sense, attempts aimed to improve teacher's mood would positively influence their levels of teaching quality (at least from their perception) and could reduce their level of fatigue. These results are in line with the need of regulating the emotional aspects as factors that influence teaching work [41,49] and may influence teachers' perception of their students' functioning and consequently increase their level of mental fatigue. It is important to note, however, that perceived fatigue is not only due to the mood or behavior of the students but will also depend on other factors related to thermal comfort as noted above. Nonetheless, with our results, it can be seen in a simple way how the temperature difference (between inside and outside) and humidity could indirectly influence perceived fatigue levels. Therefore, improving the mood in the classroom would contribute to better student learning [50].

Schools are the spaces destined to train future generations that will contribute to the socioeconomic and cultural development of different countries. Therefore, classrooms should provide healthy learning environments because it has been shown that temperature can also be affecting students' behavior. It seems clear that worse behavior in the classroom could also affect students' final performance. Therefore, classrooms should maintain adequate levels of indoor air quality and thermal comfort [18,19].

In newly built Swedish schools, it is verified how the indoor air temperature during school hours registers average values ranging from 19 to $23.5^{\circ} \mathrm{C}$, dates considered adequate in the Swedish national regulations and in the EN 15,251 [7], nowadays withdrawn. In other warmer areas, such as Jordan, both new and older schools exceeded the comfort level during the hottest hours [51]. However, the thermal environment was still more satisfactory in newly established schools, so modernization of the older school buildings seems necessary. In view of the need for further reforms, administrations have a duty to ensure that appropriate conditions are maintained in classrooms to ensure the academic performance of students $[13,18]$. To this, the authors of this study add the importance of these improvements to protect the health of the two main actors in the teaching-learning process (teacher and student).

The recommendations to create educational environments that favor learning seem not to have been exceeded in many territories when building new schools [5,21]. In the case 
of Spain, it would be interesting for schools to have green spaces in the playground and to avoid cemented areas with hardly any vegetation, and for air conditioning equipment to be a reality in all classrooms because they could be faced with the high temperatures recorded for much of the school year.

The presence of air conditioning in the schools of the Spanish Mediterranean coast should be valued very positively because the model presented in this study and the obtained results confirm that the control of the interior temperature is a determining factor influencing mood, quality of teaching and behavior of the students, preventing an increase of mental fatigue. In this line, there are studies that contemplate the use of air conditioning, the type of accommodation and the age of the subjects as determining factors in controlling fatigue [37]. In short, scientific evidence points out the need to control the temperature inside classrooms because this would facilitate a better development of the teaching-learning process that would contribute in part to reducing the current levels of school failure [18]. Regarding this measure, the energy saving should also be taken into account, but it would be a secondary concern in an educational building [9].

With regard to the limitations of this study, the absence of measurements in another recently built school and in the same city to check the possible effects of architectural influence is considered to be noteworthy. As a second limitation, other meteorological parameters such as sunlight, rainfall or wind speed could also have been taken into account. This work has also not been designed from a multisensory perspective, and the possible effects of lighting, acoustic quality and indoor air on mood, mental load and teaching capacity have been overlooked. As a third limitation, a more significant investigation should be extended also to mean radiant or the operative temperature. This is why HVAC optimal values for heating and cooling seasons in the most international standard are expressed in terms of operative temperature. Finally, this study uses instruments for measurements that do not fully comply with the recommendations of ISO 7726. However, there are studies that consider that the precision requirements cannot be due only to individual instruments (as in ISO 7726) but to measurement procedure adopted [52]. The results presented should therefore be interpreted with these limitations in consideration. Despite these limitations, from a practical point of view, we must be aware that many public schools around the world do not have access to instruments that accurately measure all the thermal variables (thermal comfort) that can influence fatigue or the mood of teachers. In this sense, and being aware of the limitations at the level of measurement, the procedure and instruments of our study are closer to the reality of schools, so we believe that the results provided can be useful for them.

As future lines of research, first is to comprehensively measure all variables on thermal comfort. Additionally, it is proposed that the work focused on environmental conditions should include a sequence of months including the different seasons of the year in order to assess their possible effects. Daily methods would be very interesting because they would reduce the retrospective bias. In addition, more studies are needed in different parts of the world because the number of studies in new climate zones would increase and much more information would be handled, even at the microlevel. In these future climate studies, industrial development and the different socioeconomic and political scenarios of the moment will have to be taken into account because of their undeniable implications. Finally, at the school level, the emergence of new studies that assess the impact of classrooms' environmental conditions according to the age of students is considered very interesting. Among the possible variables analyzed, the need to evaluate the mood of teachers with temperatures is stressed because there is no solid scientific basis [41]. For this, it is essential to develop studies that include multisensory approaches and consider variables such as the amount of C02, lighting, noise and air speed [29,30].

\section{Conclusions}

Taking into account the limitations described in the present work, a simple model has been developed that shows how indoor temperature, indoor humidity and the difference 
between outdoor and indoor temperatures predict teachers' mood and their perception of student behavior. However, in future studies, it is necessary to study in a comprehensive way the climatic variables that influence thermal comfort to analyze in depth which variables could have more weight in explaining the teachers' mood. Nonetheless, as we have previously indicated, this simple model of analysis is very close to the reality of many schools and could be useful in the short term. Therefore, and to reduce the probability that teachers register negative moods that affect their teaching quality, it seems interesting to regulate the temperature of the classrooms (i.e., by means of air conditioning) because it is a technologically controllable factor.

Author Contributions: Conceptualization, S.B.-V., E.L.-Z. and M.A.S.; methodology, S.B.-V., M.A.S. and E.S.-C.; formal analysis, E.S.-C.; investigation, S.B.-V.; resources, S.B.-V.; data curation, M.A.S. and E.S.-C.; writing-original draft preparation, S.B.-V., M.A.S. and E.L.-Z.; writing-review and editing, S.B.-V., E.L.-Z. and M.A.S.; supervision, M.A.S. All authors have read and agreed to the published version of the manuscript.

Funding: This research received no external funding.

Institutional Review Board Statement: The study was conducted according to the guidelines of the Declaration of Helsinki and approved by the Institutional Review Board (or Ethics Committee) of UNIVERSIDAD MIGUEL HERNÁNDEZ DE ELCHE (protocol code DPS.ELZ.01.14 and 12-05-2015).

Informed Consent Statement: Informed consent was obtained from all subjects involved in the study.

Data Availability Statement: The data presented in this study are available on request from the corresponding author.

Conflicts of Interest: The authors declare no conflict of interest.

\section{References}

1. Maliva, R. Intergovernmental Panel on Climate Change and Global Climate Change Projections; Springer: Cham, Switzerland, 2021; pp. 71-88.

2. Díaz, J. Cambio Climático y Salud: Adaptación a las Olas de Calor; Aranzadi: Cizur Menor, Spain, 2018.

3. Settineri, S.; Mucciardi, M.; Valentina, L.; Stefan, S.; Gioffrè, M.; Fausto, F.; Muscatello, M.R.A.; Mento, C. Metereological conditions and Psychiatric Emergency Visits in Messina, Italy. Int. J. Psychol. Res. 2016, 9, 72-82. [CrossRef]

4. Fonseca, D.; Carvalho, M.J.; Marta-Almeida, M.; Melo-Gonçalves, P.; Rocha, A. Recent trends of extreme temperature indices for the Iberian Peninsula. Phys. Chem. Earth Parts A/B/C 2016, 94, 66-76. [CrossRef]

5. Dias, M.; Bernardo, H.; Ramos, J.; Egido, M. Indoor Environment and Energy Efficiency in School Buildings—Part 1: Indoor Air Quality. In Proceedings of the 3rd International Youth Conference on Energetics, Leiria, Portugal, 7-9 July 2011 ; pp. 1-7.

6. D'Ambrosio Alfano, F.R.; Ianniello, E.; Palella, B.I. PMV-PPD and acceptability in naturally ventilated schools. Build. Environ. 2013, 67, 129-137. [CrossRef]

7. Simanic, B.; Nordquist, B.; Bagge, H.; Johansson, D. Indoor air temperatures, $\mathrm{CO}_{2}$ concentrations and ventilation rates: Long-term measurements in newly built low-energy schools in Sweden. J. Build. Eng. 2019, 25, 100827. [CrossRef]

8. Vaquero-Álvarez, M.; Álvarez-Theurer, E.; Romero Saldaña, M. Influencia de las condiciones de trabajo sobre la incapacidad temporal por contingencias comunes. Atención Primaria 2018, 50, 238-246. [CrossRef]

9. Zomorodian, Z.S.; Tahsildoost, M.; Hafezi, M. Thermal comfort in educational buildings: A review article. Renew. Sustain. Energy Rev. 2016, 59, 895-906. [CrossRef]

10. Rohat, G.; Flacke, J.; Dosio, A.; Pedde, S.; Dao, H.; van Maarseveen, M. Influence of changes in socioeconomic and climatic conditions on future heat-related health challenges in Europe. Glob. Planet. Chang. 2019, 172, 45-59. [CrossRef]

11. De Giuli, V.; Da Pos, O.; De Carli, M. Indoor environmental quality and pupil perception in Italian primary schools. Build. Environ. 2012, 56, 335-345. [CrossRef]

12. Dorizas, P.V.; Assimakopoulos, M.N.; Santamouris, M. A holistic approach for the assessment of the indoor environmental quality, student productivity, and energy consumption in primary schools. Environ. Monit. Assess. 2015, 187, 259. [CrossRef]

13. Chatzidiakou, L.; Mumovic, D.; Summerfield, A.J. What do we know about indoor air quality in school classrooms? A critical review of the literature. Intell. Build. Int. 2012, 4, 228-259. [CrossRef]

14. Chen, S.; Guo, C.; Huang, X. Air Pollution, Student Health, and School Absences: Evidence from China. J. Environ. Econ. Manag. 2018, 92, 465-497. [CrossRef]

15. Wargocki, P.; Porras-Salazar, J.A.; Contreras-Espinoza, S. The relationship between classroom temperature and children's performance in school. Build. Environ. 2019, 157, 197-204. [CrossRef]

16. Smith, R.; Bradley, G. The Influence of Thermal Conditions on Teachers' Work and Student Performance. J. Educ. Adm. 1994, 32, 34-42. [CrossRef] 
17. Xianglong, S.; Hu, Z.; Shumin, F.; Zhenning, L. Bus drivers mood states and reaction abilities at high temperatures. Transp. Res. Part F Traffic Psychol. Behav. 2018, 59, 436-444. [CrossRef]

18. Kabirikopaei, A.; Lau, J.; Nord, J.; Bovaird, J. Identifying the K-12 classrooms' indoor air quality factors that affect student academic performance. Sci. Total Environ. 2021, 786, 147498. [CrossRef]

19. Wargocki, P.; Wyon, D.P. Ten questions concerning thermal and indoor air quality effects on the performance of office work and schoolwork. Build. Environ. 2017, 112, 359-366. [CrossRef]

20. Mazlan, A.N.; Saad, S.; Yahya, K.; Haron, Z.; Hasbollah, D.; Kasiman, E.H.; Rahim, N.; Salehudddin, A. Thermal comfort study for classroom in urban and rural schools in Selangor. IOP Conf. Ser. Mater. Sci. Eng. 2020, 849, 012016. [CrossRef]

21. Lanniello, E.; D'Ambrosio Alfano, F. WS10: The REHVA Guidebook on Indoor Environment and Energy Efficiency in Schools-Part 1. Principles; REHVA: Brussels, Belgium, 2010; pp. 35-38.

22. Li, D.; Sullivan, W. Impact of views to school landscapes on recovery from stress and mental fatigue. Landsc. Urban Plan. 2016, 148, 149-158. [CrossRef]

23. Fanger, P.O. Thermal Comfort. Analysis and Applications in Environmental Engineering; Danish Technical Press: Copenhagen, Denmark, 1970.

24. Humphreys, M.; Nicol, F.; Roaf, S. Adaptive Thermal Comfort: Foundations and Analysis; Routledge: London, UK, 2015.

25. Teli, D.; Jentsch, M.F.; James, P.A.B. Naturally ventilated classrooms: An assessment of existing comfort models for predicting the thermal sensation and preference of primary school children. Energy Build. 2012, 53, 166-182. [CrossRef]

26. de Dear, R.; Schiller Brager, G. The adaptive model of thermal comfort and energy conservation in the built environment. Int. J. Biometeorol. 2001, 45, 100-108. [CrossRef]

27. Nicol, J.F.; Humphreys, M.A. Adaptive thermal comfort and sustainable thermal standards for buildings. Energy Build. 2002, 34, 563-572. [CrossRef]

28. International Organization for Standardization. (ISO7730) 2005-11-15 Ergonomics of the Thermal Environment: Analytical Determination and Interpretation of Thermal Comfort Using Calculation of the PMV and PPD Indices and Local Thermal Comfort Criteria; ISO: Geneva, Switzerland, 2005.

29. Thevenard, D.J.; Humphries, R.G. The Calculation of Climatic Design Conditions in the 2005 ASHRAE Handbook-Fundamentals. Ashrae Trans. 2005, 111, 457-466.

30. Kolokotsa, D.; Santamouris, M.; Synnefa, A.; Karlessi, T. 3.19_Passive Solar Architecture. In Comprehensive Renezwable Energy; Sayigh, A., Ed.; Elsevier: Oxford, UK, 2012; pp. 637-665.

31. Candas, V.; Dufour, A. Thermal comfort: Multisensory interactions? J. Physiol. Anthr. Appl. Hum. Sci. 2005, 24, 33-36. [CrossRef]

32. Bellia, L.; d'Ambrosio Alfano, F.R.; Fragliasso, F.; Palella, B.I.; Riccio, G. On the interaction between lighting and thermal comfort: An integrated approach to IEQ. Energy Build. 2021, 231, 110570. [CrossRef]

33. Rodríguez, C.M.; Coronado, M.C.; Medina, J.M. Thermal comfort in educational buildings: The Classroom-Comfort-Data method applied to schools in Bogotá, Colombia. Build. Environ. 2021, 194, 107682. [CrossRef]

34. Fabbri, K. Indoor Thermal Comfort Perception: A Questionnaire Approach Focusing on Children; Springer: Cham, Switzerland, 2015. [CrossRef]

35. Fantozzi, F.; Rocca, M. An Extensive Collection of Evaluation Indicators to Assess Occupants' Health and Comfort in Indoor Environment. Atmosphere 2020, 11, 90. [CrossRef]

36. Gupta, R.; O'Briuen, J.; Howard, A.; Cudmore, T. Improving Productivity in the Workplace: Lessons Learnt and Insights from the Whole Life Performance Plus Project; Oxford Brookes Univertity: Oxford, UK, 2018.

37. Fujii, H.; Fukuda, S.; Narumi, D.; Ihara, T.; Watanabe, Y. Fatigue and sleep under large summer temperature differences. Environ. Res. 2015, 138, 17-21. [CrossRef] [PubMed]

38. González-Hidalgo, G.; Sánchez-Flores, H.; López-Castellanos, G. Stress test at $44{ }^{\circ} \mathrm{C}$ and $80 \%$ of humidity and usefulness of ice suit. Rev. Med. Inst. Mex. Seguro Soc. 2011, 49, 487-492.

39. Leme, A.; Maia, I. Evaluation of Fatigue at Work in Teachers using Modern Resources in the Classroom. Procedia Manuf. 2015, 3, 4852-4859. [CrossRef]

40. Frenzel, A.; Götz, T.; Stephens, E.; Jacob, B. Antecedents and Effects of Teachers' Emotional Experiences: An Integrated Perspective and Empirical Test. In Advances in Teacher Emotion Research: The Impact on Teachers' Lives; Paul, A., Ed.; Springer: Dordrecht, The Netherlands, 2009; pp. 129-151.

41. Becker, E.S.; Goetz, T.; Morger, V.; Ranellucci, J. The importance of teachers' emotions and instructional behavior for their students' emotions-An experience sampling analysis. Teach. Teach. Educ. 2014, 43, 15-26. [CrossRef]

42. Hartel, C.; Page, K. Discrete emotional crossover in the workplace: The role of affect intensity. J. Manag. Psychol. J. Manag. Psychol. 2009, 24, 237-253. [CrossRef]

43. Klieme, E.; Pauli, C.; Reusser, K. The Pythagoras Study. Investigating effects of teaching and learning in Swiss and German mathematics classrooms. Power Video Stud. Investig. Teach. Learn. Classr. 2009, 137, 160.

44. Newton, D.P. Moods, emotions and creative thinking: A framework for teaching. Think. Ski. Creat. 2013, 8, 34-44. [CrossRef]

45. Biondi, D.; Neto, L.; Martini, A.; Marques, E. Uma Introdução ao Conforto Termo-Ambiental do Colégio Estadual Santa Gemma Galgani, Curitiba, Paraná, Brasil. Floresta 2015, 45, 409-420. [CrossRef]

46. Association, W. Declaration of Helsinki. Ethical principles for medical research involving human subjects. J. Am. Med. Assoc. 2013, 310, E1-E4. 
47. Ruiz, M.; Pardo, A.; Castellanos, R. Modelos de ecuaciones estructurales. Pap. del Psicólogo 2010, 31, $34-45$.

48. Hooper, D.; Coughlan, J.P.; Mullen, M.R. Structural Equation Modelling: Guidelines for Determining Model Fit. J. Busin. Res. Meth. 2008, 6, 53-60.

49. Jiang, J.; Vauras, M.; Volet, S.; Wang, Y. Teachers' emotions and emotion regulation strategies: Self- and students' perceptions. Teach. Teach. Educ. 2016, 54, 22-31. [CrossRef]

50. Stone, L.D.; Thompson, G.A. Classroom mood and the dance of stance: The role of affective and epistemic stancetaking in the development of a classroom mood. Learn. Cult. Soc. Interact. 2014, 3, 309-322. [CrossRef]

51. Ali, H.H.; Al-Hashlamun, R. Assessment of indoor thermal environment in different prototypical school buildings in Jordan. Alex. Eng. J. 2019, 58, 699-711. [CrossRef]

52. D'ambrosio Alfano, F.R.; Dell'Isola, M.; Palella, B.I.; Riccio, G.; Russi, A. On the measurement of the mean radiant temperature and its influence on the indoor thermal environment assessment. Build. Environ. 2013, 63, 79-88. [CrossRef] 